\title{
ANN Based DC Link Control of STATCOM in Wind Integrated Distribution System for Power Quality Conditioning
}

\author{
Sugeelin Kalai Rani \\ Department of EEE \\ Sri Chandrasekharendra Saraswathi Viswa Mahavidyalaya \\ University \\ Kanchipuram, India \\ sugeelin@rediffmail.com
}

\author{
S. Prabakaran \\ Department of EEE \\ Sri Chandrasekharendra Saraswathi Viswa Mahavidyalaya \\ University \\ Kanchipuram, India \\ prabakaran110768@gmail.com
}

\begin{abstract}
The integration of Renewable Energy Sources (RES) brings along abnormalities that affect the grid, loads, and may degrade the performance of the system. These issues can be alleviated with the integration of RES with the use of a distribution Static Synchronous Compensator (STATCOM). Renewable generation with STATCOM provides quality of power during disturbances created by the $\mathrm{AC}$ loads and intermittent power from the RES. The STATCOM distribution of DC link plays a major role in the supply quality during abnormalities. In this work, an attempt has been made to provide supply quality in the distribution system with the integration of a renewable energy farm using Artificial Neural Network (ANN)based DC link STATCOM control of distribution. The wind farm is analyzed for a Double Fed Induction Generator (DFIG) based wind turbine system and it is integrated into the distribution system. The system was simulated in MATLAB 2018A.
\end{abstract}

Keywords-double fed induction generator; distribution static synchronous compensator; artificial neural network; windfarm generation; power quality

\section{INTRODUCTION}

Wind generation plays a vital role in energy production these days due to its comparatively lower cost and environmentally friendly status as compared to conventional power generation. There is a worldwide rapid growth of wind generation plants due to the high demand for the usage of electrical energy. Wind energy generation is the most desirable non-pollutant source, it is renewable, and available in abundance [1-3]. In the early twentieth century, the aviation technology advanced rapidly and the blade technology improved. This allowed the wind turbine development with two or more blades [4-5]. At present, the wind farm was considered more economical when compared to conventional sources [67]. Wind turbines can have different sizes, depending on power requirements. The electrical generator, the rotor, speed control, and a tower are the basic components of the electrically generating wind turbines. The wind turbines may fail sometimes to safe shut down due to malfunctions [8].
Wind farm generation is installed in rural and remote places, which are usually away from the grid. Some areas have weak grid due to voltage fluctuation [9]. The supply from the induction generator is unbalanced and the torque developed by the Induction Generator (IG) varies. Due to the unbalanced current drawn by the IG, periodic pulsation torque is developed at two times the grid frequency [10]. Recent research made the wind turbines to be operated between fixed speeds to variable speed utilizing Model Predictive Control (MPC) approach which captures maximum wind energy even though wind is intermittent in nature and cannot be predicted. MPC approach gives better results when compared with a conventional PID controller [11]. This produces noise and affects the rotor shaft, the blade assembly or the gear box, causing overcurrent. To avoid these problems and in order to capture maximum wind energy, variable speed wind turbines are employed in many new wind farms. One of the components of the variable speed wind turbine is the DFIG [12-13]. The DFIG has many advantages compared to the fixed speed generators [14]. Recently, many researchers focused on the study of DFIGbased wind turbine systems which are connected to the grid. The most prominent one is the vector control of DFIG. In this case, the stator is directly integrated to the grid and the rotor is connected to magnetizing the machine. Disturbances created in the $\mathrm{AC}$ loads due to the intermittent power generated from the renewable energy leads to various power quality issues [15-16]. Therefore, the abnormalities related with grid and loads will affect the performance of the system considerably. These issues can be alleviated with the integration of RES using distribution static synchronous devices. STATCOMs are much used at the distribution level and in the installation of the end-user. Voltage regulation, power factor correction, load balancing and harmonic filtering are some of the functions that are supported by STATCOMs. Application of intelligent controllers like to compensate reactive power absorption, improves the dynamic voltage stability of a grid-connected wind power system [17]. The major advantage of a STATCOM distribution as compared to SVC's is its reduced size [18]. 
In order to improve the operational efficiency of the controller of STATCOM, various intelligent controllers have been designed to improve system stability and voltage quality. SVC and STATCOM are reactive power compensating devices and support the maintain voltage profile, however STATCOM performs better. The intermittent wind firm energy generation and the dynamic switching of load creates voltage instability and reactive power mismatch. This effect can be reduced with the use of STATCOM. Hence, the proposed work investigated the STATCOM distribution wind generation system.

The main objective of the proposed system is maintaining the DC link voltage constant and maintain the voltage profile under dynamic variations in wind generation. The grid integrated wind generation under dynamic load performance improved with STATCOM control. The DC link voltage of the STATCOM is regulated using ANN and it tries to maintain the necessary power to the load. In this paper, an attempt has been made to improve the performance of power quality in the distribution system connected with a renewable energy farm using STATCOM. The wind farm is analyzed for a DFIGbased wind turbine system integrated in the distribution system. This is studied in three different scenarios, i.e. isolated, gridintegrated, and grid-integrated using STATCOM, and compares their dynamic and transient performances under different load conditions.

\section{LITERATURE REVIEW}

Authors in [19] discuss the impact of STATCOM and Power System Stabilizer (PSS) on multi-machine power systems. They improved the damping oscillations of synchronous generators under normal and abnormal network conditions. Applying intelligent controllers with STATCOM and PSS leads to better performance than the conventional controllers'. Authors in [20] presented a distribution STATCOM reactive power source based on the magnitude of the DC link and AC voltage control. It includes a transformer, a Voltage Source Converter (VSC), and a DC link capacitor. The transformer secondary winding is connected in shunt with the grid. The VSC is constructed as an inverter. It has a capacitor bank to stabilize the DC link voltage in order to perform the converter operation. The converter also keeps the capacitor charged to the necessary voltage by maintaining the output voltage of VSC to lag the AC system voltage by a small phase angle. The phase angle is maintained at a smaller range in order to permit active power flow to compensate solid state switching and coupling transformer losses. The dynamics of the load was not taken into account. Retaining voltage and preventing overcurrent on the rotor side at the DFIG during a fault interval on the connected grid is done by using the ideal of Dynamic Voltage Restorer (DVR) in [21]. Here, the capacitor is not used intrinsically in the variable reactive source. The variable reactive source process is achieved using PWM control signals of the VSC to satisfy operational requirements. The active and reactive power dynamic exchange between the STATCOM and grid is maintained by regulating the VSC output [22]. The system dynamics was not considered.

Distribution STATCOMs do not depend on the voltage level at the PCC for compensating the current. Hence, it is not reduced as the voltage drops [23]. This is an important feature in new grid codes. Hence, reactive power is provided to the wind generators, steadily depending on the grid demand and actual voltage level. Other significant features are the provision of controllable reactive current independently of the grid voltage, the improvement of the margin of transient stability, and the improvement of power quality. Performance strategies of different controllers were compared with $\mathrm{H}_{\infty}$ in [24]. Disturbances created in the $\mathrm{AC}$ loads due to the intermittent nature of the generated power from the RES lead to reactive power mismatch and other power quality issues. Therefore, any abnormalities related with grid and loads will affect the performance of the system considerably. These issues can be alleviated with the use of distributied STATCOMs in the integration of RES [25]. Under faulty conditions, there will be fluctuations in the frequency and eventually speed differences between the grid and the interconnected wind generator creating the need for transient stability. Critical Clearing Time (CCT) with FACTS devices is longer than the one without them, which is an indication of TS improvement [26]. Hybrid systems with STATCOM have been investigated in $[27,28]$ and the grid integrated wind generation with STATCOM under dynamic load performance was presented ther for the first time. Hence, there is a need to investigate the performance under dynamic source and load conditions [29, 30].

Both source and load dyamics are considered in the proposed system and the complete and description is detailed below.

\section{PROPOSED INTEGRATED WIND FARM SYSTEM USING DISTRIBUTION STATCOMS}

The wind farm integrated to the distribution system with distribution STATCOMs connected with multiple loads and grid is shown in Figure 1.

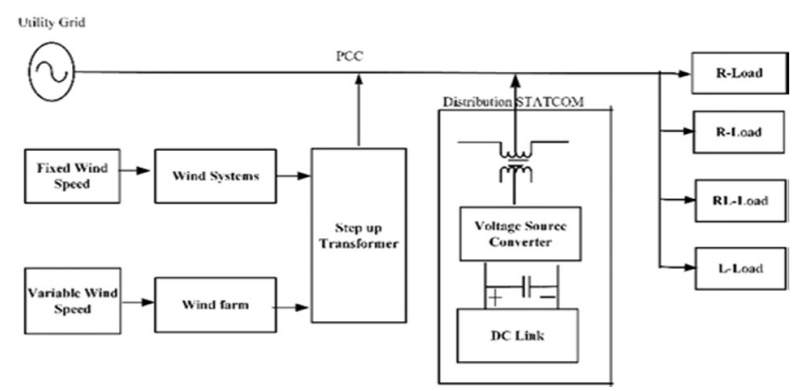

Fig. 1. Integrated windfarm using a distribution STATCOM.

A VSC based distribution STATCOM is integrated to the distribution transmission system via a shunt connected transformer. It can generate or absorb the reactive power from the bus through a controller and it is used for maintaining the voltage in distribution transmission systems. The voltage source converter is normally placed between the DC link and Point of Common Coupling (PCC). It converts the DC link power into AC power, and it supports the load and the grid during the load demand.

\section{A. Distribution STATCOM}

The distribution STATCOM has a VSC connected to a DC link and its AC side is connected in parallel across the PCC as 
shown in Figure 2. The VSC uses PWM control, hence it requires filters to overcome switching ripples. It uses a control algorithm to generate gating signals for the IGBT devices. The VSC is usually in PWM current control mode to inject the necessary current into the system. STATCOM also requires passive elements like a DC link capacitor, AC inductors, injection transformers and passive filters [31-32].

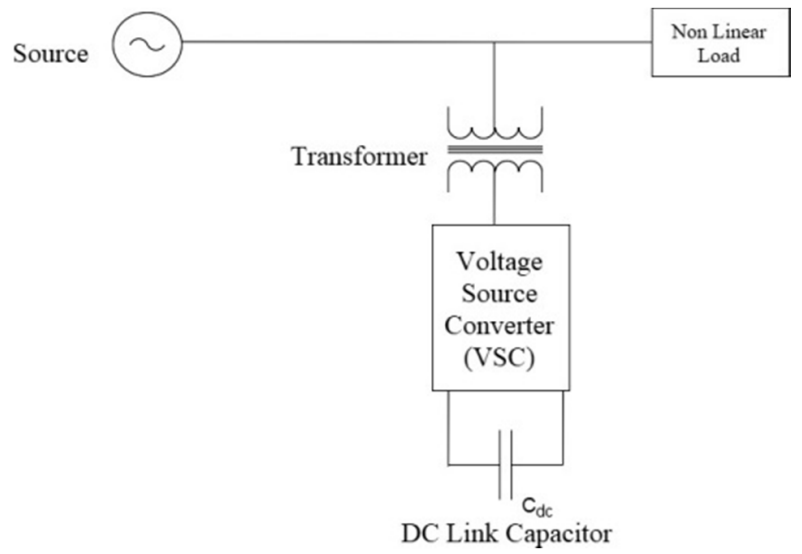

Fig. 2. Distribution STATCOM,

\section{WIND TURBINE DFIG WITH STATCOM DESIGN}

The distribution STATCOM is designed according to the requirements of wind generator. The electrical specifications of the Wind Energy System (WES) are shown in Table I. The STATCOM design includes the selection of DC link voltage, DC link capacitor, $\mathrm{AC}$ inductor, ripple filter values, voltage and current rating of the IGBT switches. The interfacing inductors and a ripple filter are used to limit the ripple in the currents and voltages.

TABLE I. WIND ENERGY SY STEM ELECTRICAL SPECIFICATION

\begin{tabular}{|c|c|}
\hline Apparent power & $2.71 \mathrm{MVA}$ \\
\hline Real power & $2.5 \mathrm{MW}$ \\
\hline Voltage & $11 \mathrm{kV}$ \\
\hline Frequency & $50 \mathrm{~Hz}$ \\
\hline Reactive power & $1.023 \mathrm{MVar}$ \\
\hline
\end{tabular}

The required rating of the distribution STATCOM depends on the reactive power demand in the system. An uncontrolled rectifier contributes to lower order harmonics particularly of the fifth and seventh order, is considered as a nonlinear load and is connected to the PCC. A three leg VSC is used in this design. This configuration contains IGBTs, inductors, and a $\mathrm{DC}$ capacitor. The required reactive power of $1.53 \mathrm{MV}$ ar comes from an $11 \mathrm{KV}, 50 \mathrm{~Hz}$ three phase system with compensation from STATCOM. The compensation support from distribution STATCOM depends on the rating of the VSC components. The VSC is designed for compensating and it decides the rating of the VSC components. During grid drop, the reactive power demand may vary. Similarly, nonlinear load connected to the PCC contributes harmonics and considerably increases reactive power requirement. Considering both aspects leads to $50 \%$ variation in reactive power. Hence, it is selected to $1.53 \mathrm{MVar}$.

\section{ANN-BASED DC LINK CONTROL OF STATCOM}

ANNs are computing systems inspired by the biological neural networks that constitute animal brains. Such systems progressively improve their performance on doing tasks. They have found most use in applications difficult to express in a traditional computer algorithm using rule-based programming. An ANN is based on a collection of connected units called artificial neurons. Each connection (synapse) between neurons can transmit a signal to another neuron. The receiving neuron can process the signal(s) and then signal the downstream neurons that are connected to it. Neurons may have states, generally represented by real numbers, typically between 0 and 1 . Neurons and synapses may also have a weight that varies as learning proceeds, which can increase or decrease the strength of the signal that it sends downstream. Further, they may have a threshold such that only if the aggregate signal is below (or above) that level the downstream signal is sent. Typically, neurons are organized in layers. Different layers may perform different kinds of transformations on their inputs. Signals travel from the first (input), to the last (output) layer, possibly after traversing the layers multiple times. The original goal of the ANN approach was to solve problems in the same way that a human brain would. Over time, attention focused on matching specific mental abilities, leading to deviations from biology such as backpropagation. ANNs have been used on a variety of tasks, including computer vision, speech recognition, machine translation, social network filtering, playing board and video games, medical diagnosis, etc.

The DC link with ANN control of distribution STATCOM is shown in Figure 3. The layout of the ANN is shown in Figure 4 and the simulink model of the proposed system is given in Figure 5.

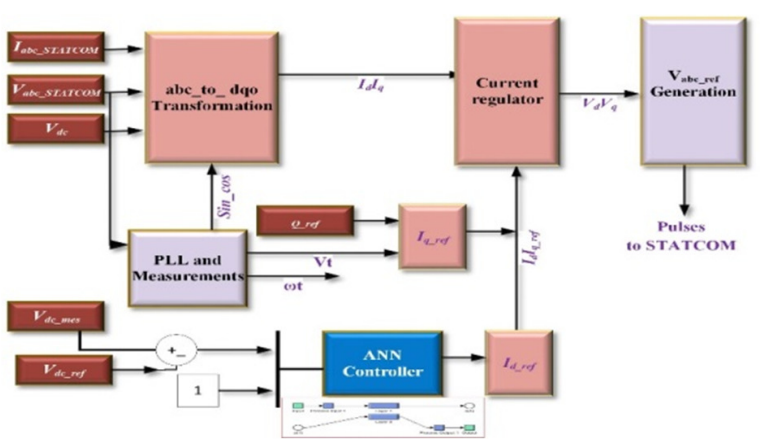

Fig. 3. Distribution STATCOM control.

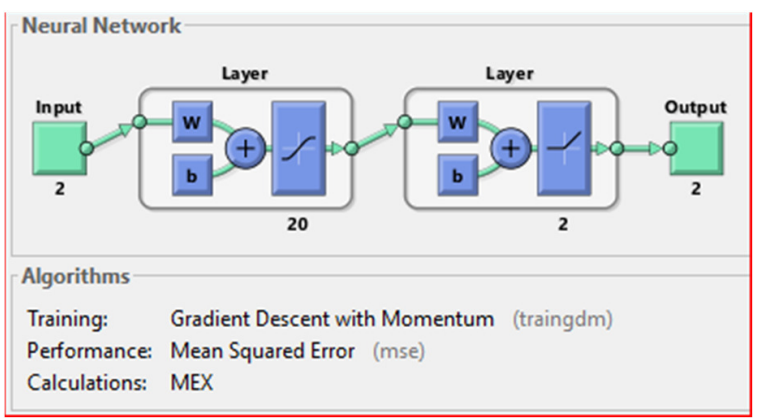

Fig. 4. ANN control layout. 


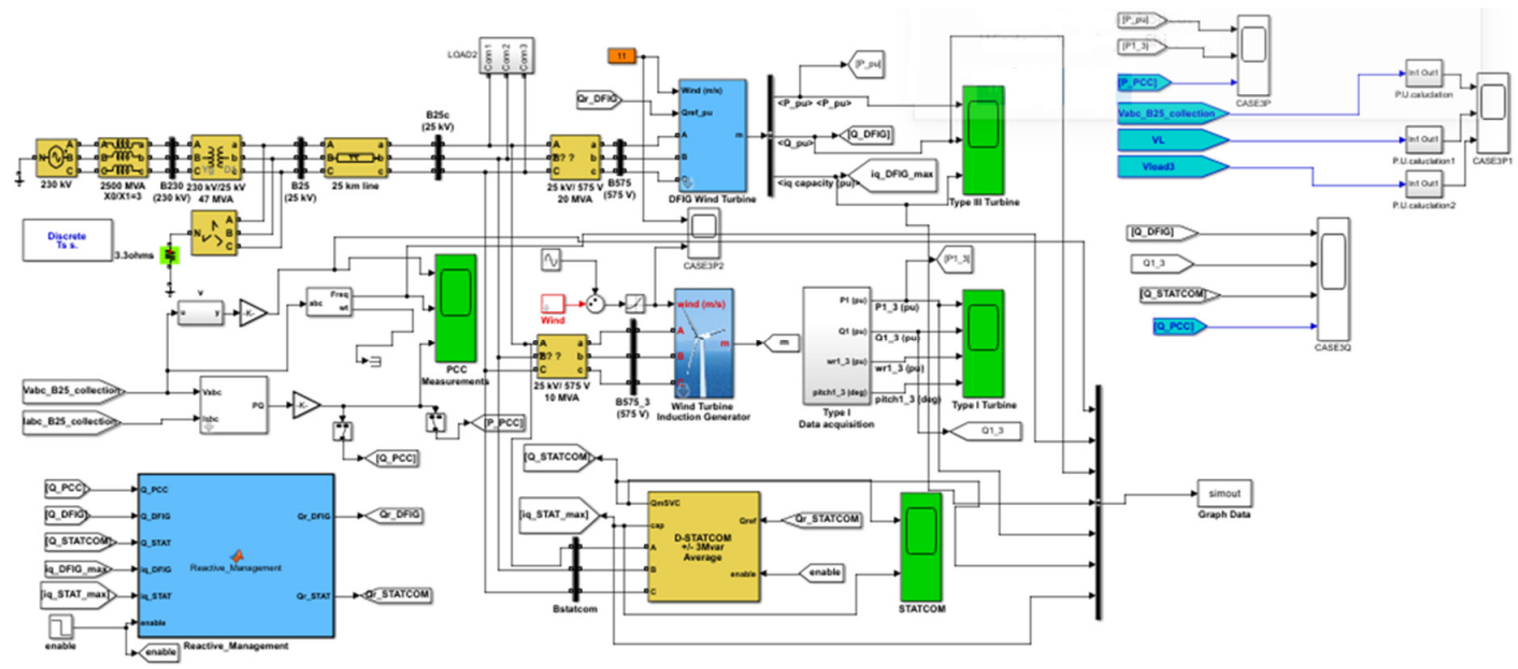

Fig. 5. Simulink model of the proposed system.

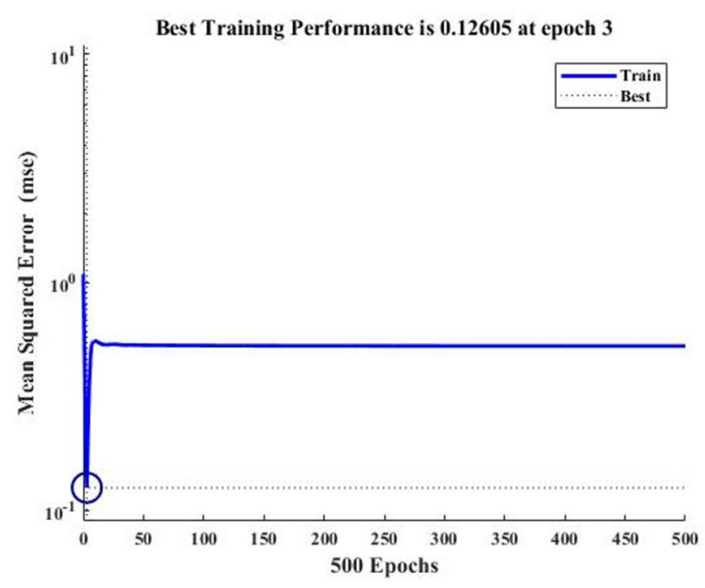

Fig. 6. Performance of ANN.
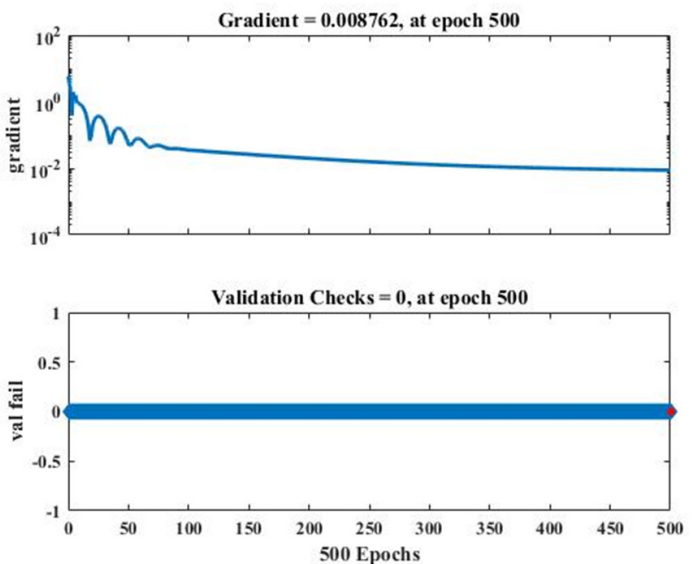

Fig. 7. Training of ANN.

Figures 6-8 represent the performance of ANN which depends on the DC link voltage. The mean squared error of the training performance of the ANN is 0.012605 and the gradient is 0.008762 at 500 epochs.

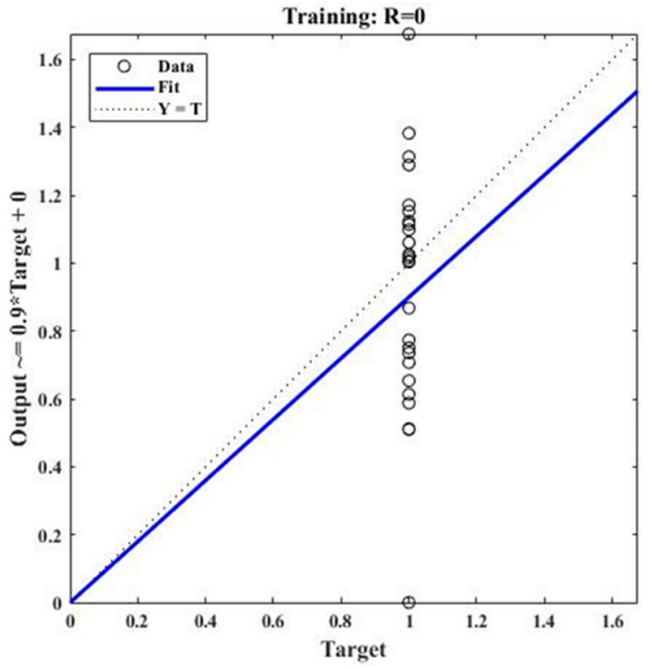

Fig. 8. Regression of ANN.

\section{SIMULINK RESULTS}

The performance of the proposed system under wind changing wind, sudden switching of inductive load, and voltage variation is investigated below.

\section{A. Wind Speed Characteristics}

Figures 9-10 show the wind profile of Gennerators 1 and 2 respectively. Generator-1 is considered as the base generation. Generatore-2 is considered only for creating dynamic variations in generation.

\section{B. Switching of Loads}

The dynamic switching of the RL and inductive load has been presented in different intervals at $\mathrm{t}=0.3$ to $0.5 \mathrm{~s}$ and 0.5 to $0.9 \mathrm{~s}$ respectively. The load voltages are shown in Figure 11. Dynamic switching of inductive load $\mathrm{t}=0.3 \mathrm{~s}$ to $\mathrm{t}=0.9 \mathrm{~s}$ is shown in Figure 11. During this period the voltage profile improved with the use of STATCOM. 


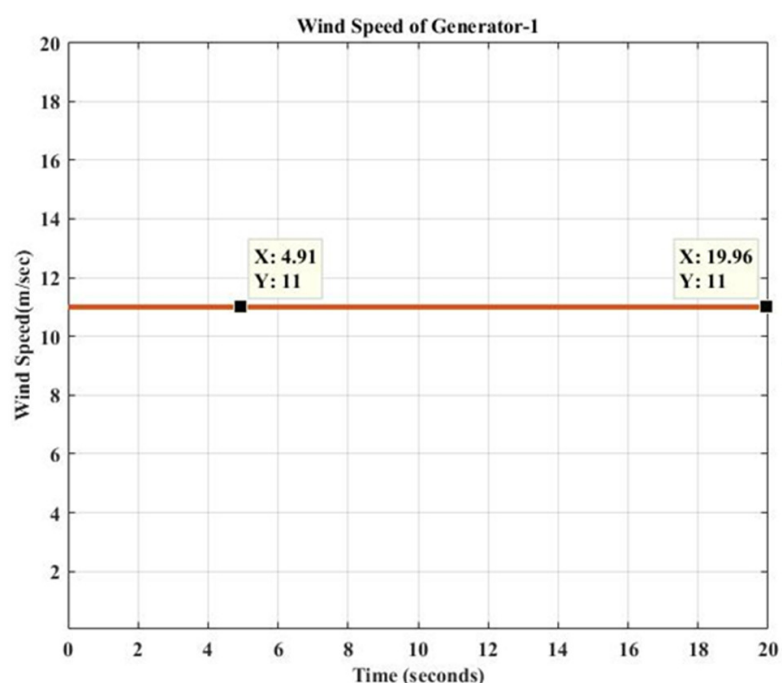

Fig. 9. Wind profile of Generator-1.

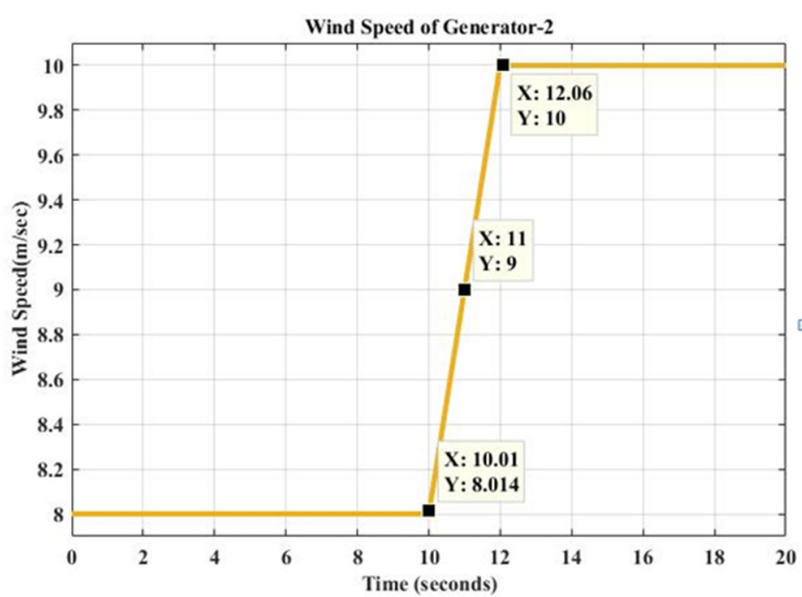

Fig. 10. Wind profile of Generator-2.
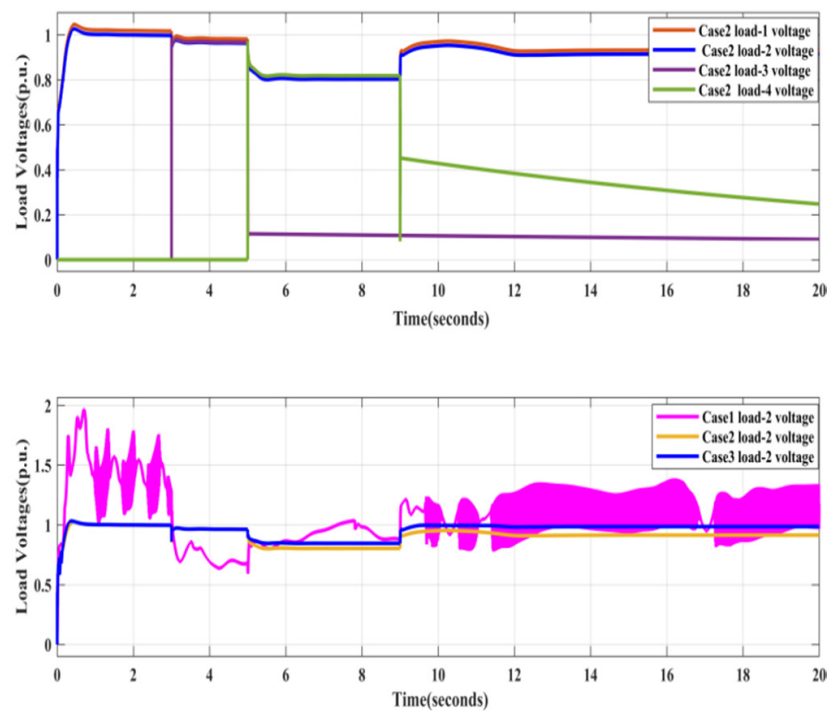

Fig. 11. Load voltage.
C. Grid Active Power, Reactive Power, and Time Characteristics

Grid power in isolated Case-1 net power delivery is zero $\left(P_{n e t}, Q_{n e t}\right)=0$. The grid integrated mode active and reactive powers in Cases 2 and 3 are shown in Figure 12. Active and reactive power delivery in Case- 2 is less than in Case- 3 . In Case-3 the reactive power was supported with the STATCOM and the burden on the grid was reduced.
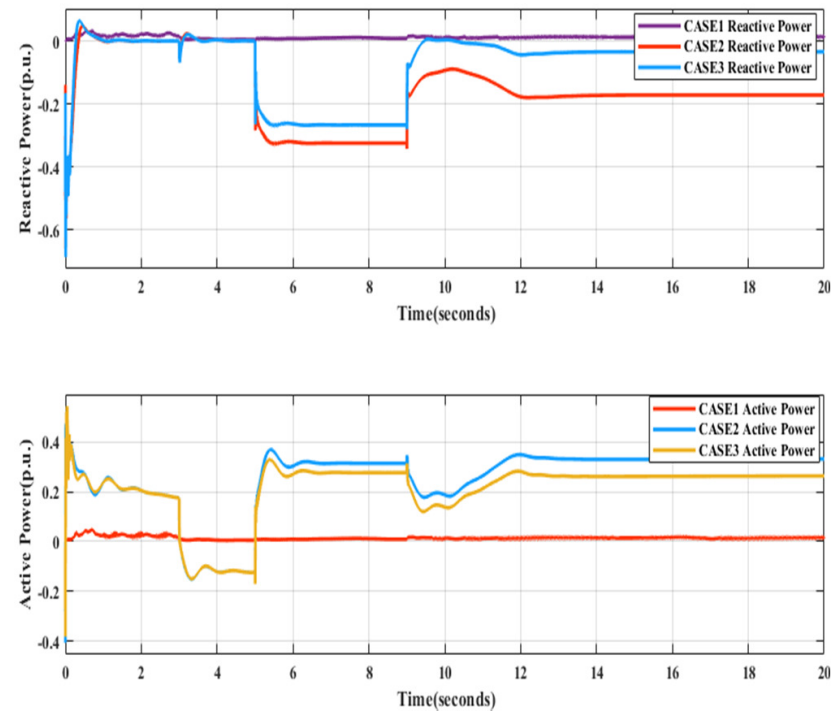

Fig. 12. Grid active and reactive power.

\section{Load Active Power, Reactive Power and Time}

\section{Characteristics}

The dynamic switching of the four loads reactive performance is shown in Figure 13. Load 1 and Load 2 are restive loads, Load 3 is R-L load and Load 4 is the inductive load. The reactive performance according to the dynamic switching of the four loads is shown in Figure 13. Load 1 and Load 2 reactive power is zero hence the loads are resistive loads.

\section{E. STATCOM Reactive Power - Time Characteristics}

In Cases 1 and 2, the STATCOM is not integrated in the system. The reactive power exchange is shown in Figure 14. Initially, the reactive power support is more due to insufficient sharing power from wind generation.At $t=4 s$ to $t=12 s$ the change in the inductive load requires the necessary reactive power and it is supported with STATCOM as shown in Figure 14. In Case- 1 the voltage drop variations is more during the $\mathrm{t}=0.3 \mathrm{~s}$ to $\mathrm{t}=0.9 \mathrm{~s}$ interval. The power is insufficient to meet the increased load demand, resulting in a voltage drop at the bus. In Case-2, the voltage profile is improved compared to Case-1 due to grid support. But the voltage profile suffers due to switching of large inductive load including resistive loads. Still, there is a need to improve the voltage profile further. In Case-3, the distribution STATCOM supports the counter effect of reactive power generated by the inductive load on the grid. The results in Case-3 show the better voltage profile improvement compared to Cases 1 and 2. 

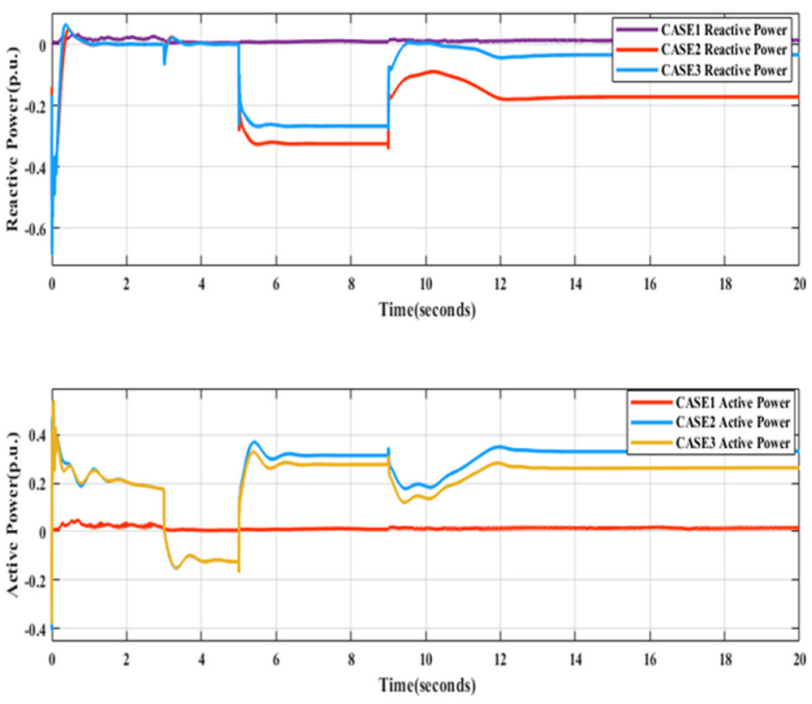

Fig. 13. Loads active and reactive power performance.

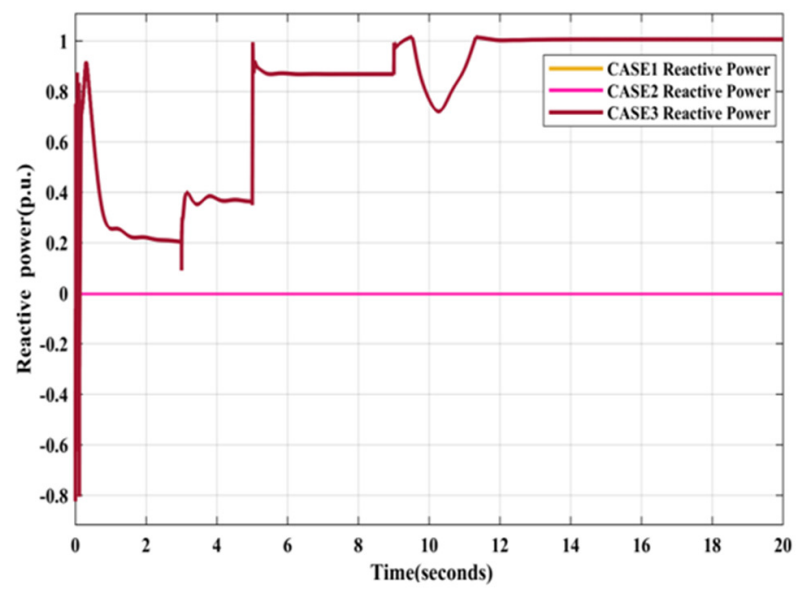

Fig. 14. STATCOM reactive power.

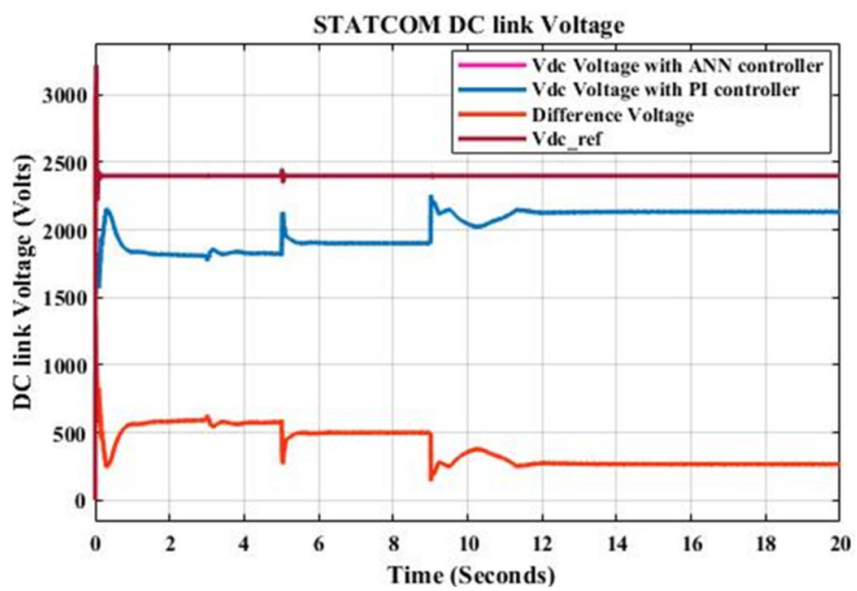

Fig. 15. DC link voltage of STATCOM.

The STATCOM DC link voltage with PI, ANN controller is shown in Figure 15. The performance of STATCOM under dynamic switching of loads affects the DC link voltage and it is stabilized with the ANN controller. From the results it can be inferred that the ANN controller performs satisfactorily.

\section{CONCLUSION}

The performance of a DFIG based windfarm using distribution STATCOM is analyzed under different load dynamics. The distribution grid maintains constant voltage and the necessary active and reactive power of the proposed system in the third case compared to the other scenarios. The system is stabilized even during fluctuating wind speed and the occurrence of varying AC load. It was shown that the effective work of the STATCOM made the system more reliable. The results show that the obtained voltage profile is maintained with the distribution STATCOM, which is effectively control of the DC link voltage with ANN under undesirable effects. The DC link voltage is stabilized with the ANN controller.

\section{REFERENCES}

[1] G. M. Shafiullah, M. T. Arif, and A. M. T. Oo, "Mitigation strategies to minimize potential technical challenges of renewable energy integration," Sustainable Energy Technologies and Assessments, vol. 25, pp. 24-42, Feb. 2018, doi: 10.1016/j.seta.2017.10.008.

[2] I. J. Raglend and R. Dharavath, "Intelligent Controller based Solar Photovoltaic with Battery Storage, Fuel Cell Integration for Power Conditioning," International Journal of Renewable Energy Research (IJRER), vol. 9, no. 2, pp. 859-867, Jun. 2019.

[3] R. Dharavath and I. J. Raglend, "Fuzzy Controller Based Solar Photovoltaic System, Fuel Cell Integration for Conditioning the Electrical Power," Journal of Green Engineering, vol. 8, no. 3, pp. 301318, Jul. 2018, doi: 10.13052/jge1904-4720.835.

[4] W. Qiao and R. G. Harley, "Improved Control of DFIG Wind Turbines for Operation with Unbalanced Network Voltages," in 2008 IEEE Industry Applications Society Annual Meeting, Oct. 2008, pp. 1-7, doi: 10.1109/08IAS.2008.153.

[5] T. Brekken, N. Mohan, and T. Undeland, "Control of a doubly-fed induction wind generator under unbalanced grid voltage conditions," in 2005 European Conference on Power Electronics and Applications, Sep. 2005, doi: 10.1109/EPE.2005.219315.

[6] P. D. Chung, "Evaluation of Reactive Power Support Capability of Wind Turbines," Engineering, Technology \& Applied Science Research, vol. 10, no. 1, pp. 5211-5216, Feb. 2020.

[7] E. Jamil, S. Hameed, B. Jamil, and Qurratulain, "Power quality improvement of distribution system with photovoltaic and permanent magnet synchronous generator based renewable energy farm using static synchronous compensator," Sustainable Energy Technologies and Assessments, vol. 35, pp. 98-116, Oct. 2019, doi: 10.1016/j.seta.2019.06.006.

[8] J. Morren and S. W. H. de Haan, "Ridethrough of wind turbines with doubly-fed induction generator during a voltage dip," IEEE Transactions on Energy Conversion, vol. 20, no. 2, pp. 435-441, Jun. 2005, doi: 10.1109/TEC.2005.845526.

[9] Z. Miao and L. Fan, "The art of modeling and simulation of induction generator in wind generation applications using high-order model," Simulation Modelling Practice and Theory, vol. 16, no. 9, pp. 12391253, Oct. 2008, doi: 10.1016/j.simpat.2008.06.007.

[10] R. Pena, R. Cardenas, E. Escobar, J. Clare, and P. Wheeler, "Control strategy for a Doubly-Fed Induction Generator feeding an unbalanced grid or stand-alone load," Electric Power Systems Research, vol. 79, no. 2, pp. 355-364, Feb. 2009, doi: 10.1016/j.epsr.2008.07.005.

[11] H. Bassi and Y. A. Mobarak, "State-Space Modeling and Performance Analysis of Variable-Speed Wind Turbine Based on a Model Predictive Control Approach," Engineering, Technology \& Applied Science Research, vol. 7, no. 2, pp. 1436-1443, Apr. 2017. 
[12] A. D. Hansen and G. Michalke, "Fault ride-through capability of DFIG wind turbines," Renewable Energy, vol. 32, no. 9, pp. 1594-1610, Jul. 2007, doi: 10.1016/j.renene.2006.10.008.

[13] J. B. Ekanayake, L. Holdsworth, XueGuang Wu, and N. Jenkins, "Dynamic modeling of doubly fed induction generator wind turbines," IEEE Transactions on Power Systems, vol. 18, no. 2, pp. 803-809, May 2003, doi: 10.1109/TPWRS.2003.811178.

[14] S. Li and T. A. Haskew, "Analysis of Decoupled d-q Vector Control in DFIG Back-to-Back PWM Converter," in 2007 IEEE Power Engineering Society General Meeting, Jun. 2007, pp. 1-7, doi: 10.1109/PES.2007.385461

[15] R. Dharavath, I. J. Raglend, J. B. Edward, and S. A. Shaaban, "Grid Connected Solar Photovoltaic-Fuel Cell Based Hybrid System with Dynamic Voltage Restorer," Journal of Advanced Research in Dynamical and Control Systems, vol. 9, no. issue 8, pp. 09-17, Oct. 2017.

[16] R. W. Mosobi, T. Chichi, and S. Gao, "Power quality analysis of hybrid renewable energy system," Cogent Engineering, vol. 2, no. 1, Dec. 2015, doi: 10.1080/23311916.2015.1005000, Art no. 1005000 .

[17] D. N. Truong and V. T. Bui, "Hybrid PSO-Optimized ANFIS-Based Model to Improve Dynamic Voltage Stability," Engineering, Technology \& Applied Science Research, vol. 9, no. 4, pp. 4384-4388, Aug. 2019.

[18] R. Dharavath and I. J. Raglend, "Integration of Utility Grid with Hybrid Generation for Power Quality Conditioning Using Dynamic Voltage Restorer," International Journal of Renewable Energy Research (IJRER), vol. 9, no. 1, pp. 56-64, Mar. 2019.

[19] G. Shahgholian, E. Mardani, and A. Fattollahi, "Impact of PSS and STATCOM Devices to the Dynamic Performance of a Multi-Machine Power System," Engineering, Technology \& Applied Science Research, vol. 7, no. 6, pp. 2113-2117, Dec. 2017.

[20] L. Dusonchet, F. Massaro, and E. Telaretti, "Transient stability simulation of a fixed speed wind turbine by Matlab/Simulink," in 2007 International Conference on Clean Electrical Power, May 2007, pp. 651-655, doi: 10.1109/ICCEP.2007.384308.

[21] P. D. Chung, "Voltage Enhancement on DFIG Based Wind Farm Terminal During Grid Faults," Engineering, Technology \& Applied Science Research, vol. 9, no. 5, pp. 4783-4788, Oct. 2019.

[22] N. K. Saxena and A. Kumar, "Dynamic Reactive Power Compensation and Cost Analysis for Isolated Hybrid Power System," Electric Power Components and Systems, vol. 45, no. 18, pp. 2034-2049, Nov. 2017, doi: 10.1080/15325008.2017.1332116.

[23] K. Basaran, N. S. Cetin, and S. Borekci, "Energy management for ongrid and off-grid wind/PV and battery hybrid systems," IET Renewable Power Generation, vol. 11, no. 5, pp. 642-649, Winter 2017, doi: 10.1049/iet-rpg.2016.0545.

[24] S. L. S. Louarem, D. E. C. Belkhiat, T. Bouktir, and S. Belkhiat, "An Efficient Active and Reactive Power Control of DFIG for a Wind Power Generator," Engineering, Technology \& Applied Science Research, vol. 9, no. 5, pp. 4775-4782, Oct. 2019.

[25] Y. Tang, H. He, Z. Ni, J. Wen, and T. Huang, "Adaptive Modulation for DFIG and STATCOM With High-Voltage Direct Current Transmission," IEEE Transactions on Neural Networks and Learning Systems, vol. 27, no. 8, pp. 1762-1772, Aug. 2016, doi: 10.1109/TNNLS.2015.2504035.

[26] N. E. Akpeke, C. M. Muriithi, and C. Mwaniki, "Contribution of FACTS Devices to the Transient Stability Improvement of a Power System Integrated with a PMSG-based Wind Turbine," Engineering, Technology \& Applied Science Research, vol. 9, no. 6, pp. 4893-4900, Dec. 2019.

[27] G.Sreenivasan and K.Sudarsan, "Power Quality Enhancement in Grid Connected Hybrid PV/WT System using Tree Seed Algorithm with RNN," Helix, vol. 10, no. 2, pp. 211-218, Apr. 2020.

[28] S. S. Rangarajan, J. Sharma, and C. Sundarabalan, "Novel Exertion of Intelligent Static Compensator Based Smart Inverters for Ancillary Services in a Distribution Utility Network-Review," Electronics, vol. 9 , no. 4, Apr. 2020, doi: 10.3390/electronics9040662, Art no. 662 .
[29] V. H. Nguyen, H. Nguyen, M. T. Cao, and K. H. Le, "Performance Comparison between PSO and GA in Improving Dynamic Voltage Stability in ANFIS Controllers for STATCOM," Engineering, Technology \& Applied Science Research, vol. 9, no. 6, pp. 4863-4869, Dec. 2019.

[30] Y. Jeon et al., "An Enhanced Static Compensator With DC-Link Voltage Shaping Method," IEEE Transactions on Power Electronics, vol. 35, no. 3, pp. 2488-2500, Mar. 2020, doi: 10.1109/TPEL.2019.2928367.

[31] M. Mangaraj and A. K. Panda, "Modelling and simulation of KHLMS algorithm-based DSTATCOM," IET Power Electronics, vol. 12, no. 9, pp. 2304-2311, Aug. 2019, doi: 10.1049/iet-pel.2018.5625.

[32] C. Kumar and M. K. Mishra, "A Voltage-Controlled DSTATCOM for Power-Quality Improvement," IEEE Transactions on Power Delivery, vol. 29, no. 3, pp. 1499-1507, Jun. 2014, doi: 10.1109/TPWRD.2014.2310234. 